\title{
Strategi Pengembangan Usaha Keluarga Skala Mikro di Kota Palembang
}

\author{
Yulizar Kasih, Charisma Ayu P* \\ Program Studi Manajemen, STIE Multi Data Palembang, Palembang, Indonesia \\ *charisma@stie-mdp.ac.id
}

\begin{abstract}
The purpose of this study is to determine the characteristics of the family business, internal strategic factors (strengths and weaknesses) and external (opportunities and threats) of the family business. This study analyzes various strategic alternatives that will be selected as a family business development strategy, then to determine the main strategies that can be implemented. ess by compiling a strategic business plan, implement the cooperation with external parties in the form of training and assistance related to product quality improvement, product innovation, preparation of financial rep This research is a descriptive study with 43 respondents as the research object selected by purposive and convenience sampling technique. The analyzed data uses descriptively by IFE-EFE matrix analysis and the SWOT matrix. The results from this study show that the family business was in a growth strategy position. Business development was carried out by increasing the scale of the busin orts, processing business licenses, online marketing (digital marketing), preparation of credit proposals, build the relationships with suppliers and maintain wellestablished relationships with customers.
\end{abstract}

Keywords : Development Strategy, Family Business, SMEs

\section{PENDAHULUAN}

Di Indonesia sektor UMKM memiliki proporsi sebesar $99,99 \%$ dari total pelaku usaha di Indonesia atau sebanyak 57,89 juta unit dan didominasi oleh Usaha Mikro mencapai 98,77\%. Pada tahun 2013, peran Usaha Mikro terhadap PDB sebesar 30,25\% dari total $57,55 \%$ untuk keseluruhan UMKM. Selanjutnya mampu menyerap tenaga kerja sebesar 88,90\% (Kemenkop \& UKM, www.smecda.com), serta mampu menyumbang volume ekspor sebesar $14.06 \%$ atau Rp166,63 triliun dari total ekspor nasional (Bank Indonesia, 2015).

Di sisi lain, bisnis keluarga menempati posisi penting dalam perekonomian suatu negara, dalam bentuk kontribusi terhadap penyerapan tenaga kerja, produk domestik bruto, jumlah unit usaha, pembayaran pajak, memenuhi kebutuhan barang dan jasa, dan memberdayakan masyarakat (Susanto, 2005). Di Negara Eropa, 70\%-80\% merupakan bisnis keluarga yang mampu menyerap tenaga kerja sebesar 40\%-50\% dan memberikan nilai GDP antara 20\%-70\% (Mandi, 2008). Sementara di USA, bisnis keluarga memberikan kontribusi terhadap nilai GDP sampai $49 \%$ dan menciptakan lapangan kerja baru sebesar $78 \%$ (Craig et al., 2008). Kontribusi bisnis keluarga di negara berkembang dan negara maju terhadap Produk Domestik Bruto 
(PDB) adalah sebesar 60\%-70\% (Vani et al., 2014).

Di Indonesia sendiri jumlah perusahaan keluarga memegang peranan yang sangat strategis terhadap perekonomian nasional. Peran penting bisnis keluarga sejalan dengan peran strategis UMKM baik dalam penyerapan tenaga kerja, sumbangan terhadap Gross Domestic product (GDP), dan jumlah usaha yang dominan. Di beberapa negara peranan UMKM dalam menciptakan lapangan pekerjaan sangat signifikan. Di European Union (EU), UMKM mampu menciptakan sekitar 90 juta pekerjaan, di Netherlands, SMEs mampu mempekerjaan 55\% dari total tenaga kerja, di Australia SMEs dapat menciptakan 51\% lapangan kerja swasta, di Italy SMEs dapat menyerap 2,2 million dari tenaga kerja nasional. Peranan dalam meningkatkan GDP di beberapa negara juga cukup signifikan, misalnya di China mencapai 60,0 \%, Jerman $57,0 \%$, Jepang $55,3 \%$, Korea $50,0 \%$ dan Malaysia 47,3\% (Katua, 2014).

\section{Bisnis Keluarga}

Usaha mikro identik dengan usaha keluarga. Hal ini dikarenakan tenaga kerja yang bekerja di usaha mikro umumnya berasal dari anggota keluarga sendiri (Rahim \& Karana, 2014; Kuncoro, 2013). Usaha Mikro Kecil dan Menengah, Usaha Mikro adalah usaha produktif milik orang perorang dan atau badan usaha perorangan yang memenuhi kriteria usaha mikro, memiliki kekayaan bersih paling banyak Rp50.000.000,00 tidak termasuk tanah dan bangunan usaha; atau memiliki hasil penjualan tahunan paling banyak Rp300.000.000.00 (UU No. 20 Tahun 2008)

Bisnis keluarga merupakan sebuah bisnis yang unik (Ingalsuo, 2014), dibandingkan dengan bisnis non keluarga, terutama dalam hal karakteristik, pengelolaan, dan permasalahan yang dihadapi. Bisnis keluarga didefinisikan secara beragam. Stefan (2010) mendefinisikan bisnis keluarga sebagai usaha yang dimiliki dan/atau dikelola oleh sejumlah orang yang memiliki hubungan keluarga, baik suami-istri, keturunan, atau hubungan persaudaraan. Susanto (2005) dalam rangkumannya menjelaskan bahwa sebuah perusahaan disebut perusahaan keluarga bila terdapat dua atau lebih anggota keluarga atau dua generasi yang terlibat baik dalam mengawasi keuangan keluarga maupun kebijakan perusahaan. Definisi serupa juga dikemukakan oleh beberapa peneliti, yang menunjukkan adanya keterlibatan peran anggota keluarga sebagai pemilik, pemimpin, pendiri, pengelola, dan pengontrol (European Commission, 2009; Laksitareni, 2015; Vani et al., 2014).

Bila dibandingkan dengan usaha kecil dan usaha menengah, usaha mikro lebih banyak menghadapi masalah dan kendala dalam operasional sehari-hari maupun dalam pengembangan ke depan. Permasalahan dan kendala tersebut melekat dan menjadi ciri atau karakteristik yang dapat dijadikan acuan dalam mengenali usaha mikro. Secara khusus karakteristik usaha mikro antara lain: 1) jenis barang/komoditi yang dijual cenderung berubah-ubah, 2) tempat usaha cenderung berpindah-pindah, (3) belum memiliki administrasi keuangan yang sederhana sekalipun, 4) keuangan keluarga masih bercampur keuangan usaha, 5) pemilik usaha atau pelaku usaha belum memiliki jiwa wirausaha yang memadai, 6) tingkat pendidikan pemilik atau pelaku usaha relatif rendah, 7) pelaku usaha secara umum belum mampu mengakses permodalan bank, tetapi sudah banyak yang memanfaatkan lembaga keuangan non-bank, 8) pelaku usaha memiliki keterbatasan dalam memenuhi beberapa persyaratan dan prosedur bank, dan 9) umumnya tidak memiliki izin usaha atau persyaratan legalitas lainnya termasuk NPWP (Kasih, 2019).

Dari sisi skala usaha, berdasarkan studi yang dilakukan oleh beberapa peneliti terhadap UMKM di beberapa Kota di Indonesia (Urata et al., 2000; Kuncoro, 2013; Alyas \& Rakib, 2017; Pangestika et al., 2016; Utomo, 2017; Hamid \& Susilo, 2011). dapat terindikasi bahwa paling tidak ada 4 permasalahan yang mendasar yang masih dihadapi oleh usaha mikro di 
Indonesia antara lain: 1) masih terbatasnya permodalan usaha disebabkan sulitnya akses terhadap sumber permodalan terutama perbankan; 2) ketidakmampuan dalam memasarkan (mempromosikan) hasil produksi; 3) rendahnya kualitas SDM (pendidikan, keterampilan teknis dan manajerial); dan 4) masih rendahnya kapasitas produksi, akses bahan baku, teknologi produksi, dan kualitas produk. Lebih lanjut tantangan yang dihadapi oleh usaha mikro adalah bagaimana menjaga dan mempertahankan kelangsungan hidup usahanya. Sedangkan bagi pelaku usaha yang usahanya sudah berjalan baik menghadapi tantangan yang lebih berat yaitu bagaimana cara mengembangkan usaha lebih lanjut (Kuncoro, 2013), misalnya terkait keterlibatan keluarga, pertumbuhan bisnis, pengaruh lingkungan eksternal, masalah internal organisasi, rencana suksesi (pewarisan usaha) ke generasi selanjutnya.

\section{Karakteristik dan Permasalahan Bisnis Keluarga}

Bisnis atau usaha keluarga memiliki karakteristik tersendiri dan berbeda dengan bisnis non keluarga. Perbedaan ini disebabkan oleh sistem kepemilikan, pengelolaan, atau pengawasan yang didominasi oleh keluarga (European Commission, 2009). Menurut Susanto (2005), perusahaan keluarga di Indonesia memiliki karakteristik: 1) adanya keterlibatan keluarga, 2) lingkungan yang saling berbagi, 3) tingginya saling keterandalan, 4) adanya unsur kekuatan emosi, 5) hubungan yang bersifat kurang formal, dan 6) adanya praktik kepemimpinan ganda. Karakteristik lain yang dimiliki oleh perusahaan keluarga adalah biasanya posisi kunci dalam perusahaan dipegang oleh keluarga, keuangan perusahaan belum dipisahkan dengan keuangan keluarga, tidak adanya mekanisme pertanggung jawaban yang ketat, motivasi kerja yang tinggi, serta tidak adanya kekhususan dalam menajemen (Tugiman, 1995). Di luar negeri, perusahaan keluarga memiliki karakteristik yang relatif sama dengan Indonesia. European
Commission (2009) mengemukakan beberapa karakteristik perusahaan keluarga antara lain : 1) mayoritas hak dalam pengambilan keputusan berada pada orangorang yang memiliki perusahaan atau anggota keluarganya, 2) mayoritas hak pengembilan keputusan biasanya langsung atau tidak langsung, 3) paling tidak satu perwakilan keluarga atau kerabat secara resmi terlibat dalam tata kelola perusahaan, 4) kepemilikan saham sebesar 25\% memberikan hak dalam pengambilan keputusan. Qurashi et al. (2013) menambahkan bahwa perusahaan keluarga memiliki tujuan bisnis yang berbeda dengan non keluarga, suksesi ditentukan oleh pemilik perusahaan keluarga, pembuat kebijakan memainkan peranan utama dalam mendorong bisnis keluarga untuk tumbuh dan bertahan.

Pengelolaan bisnis keluarga tidak terlepas dari permasalahan yang dihadapi saat ini, pada masa yang akan datang, sekaligus tantangan yang akan dihadapi bagi pengembangan dan keberlanjutan bisnis dan keluarga. Permasalahan yang dihadapi oleh bisnis keluarga di Indonesia merupakan bauran permasalahan yang saling melekat satu sama lain yaitu masalah dari sisi manajemen bisnis keluarga dan masalah dari sisi skala usaha (UMKM).

Dari sisi manajemen bisnis keluarga, permasalahan yang sering dihadapi dan sekaligus tantangan dalam pengembangan usaha keluarga antara lain: konflik keluarga dan bagaimana menyelesaikannya, adanya nepotisme dalam rekrutmen karyawan, suksesi kepemilikan dan kepemimpinan, pengaturan keterlibatan anggota keluarga (Steier et al., 2015; Ingalsuo, 2014). Selain dari itu, secara spesifik Susanto (2005) mengemukakan potensi permasalahan dan tantangan perusahaan keluarga antara lain adalah: 1) banyaknya anggota keluarga yang ikut mengatur perusahaan; 2) pembagian kompensasi atau penghargaan yang tidak adil; 3) terdapat toleransi kepada anggota keluarga yang tidak memiliki kompetensi; 4) kecenderungan pendapatan perusahaan tersedot untuk keluarga; 5) terbatasnya akses 
di pasar modal; dan 6) rentan terhadap kritik dari luar keluarga.

Baik dari sisi manajemen usaha maupun dari sisi skala usaha mikro, usaha keluarga sampai saat ini masih menghadapi berbagai kendala dan permasalahan. Dari sisi manajemen usaha keluarga, permasalahan yang menghambat perkembangan usaha keluarga terfokus pada konflik keluarga, nepotisme rekrutmen anggota keluarga yang tidak berkompeten, suksesi kepemimpinan, administrasi keuangan, dan kompensasi yang kurang adil (Steier et al., 2015; Ingalsuo, 2014; Susanto, 2005).

Permasalahan tersebut menyebabkan usaha keluarga sulit untuk berkembang dan bersaing dengan perusahaan skala yang lebih besar dan rata-rata hanya mampu bertahan selama 10 tahun (Palupijati \& Indarti, 2013), sehingga tidak heran jika hanya sebesar $30 \%$ dari keseluruhan bisnis keluarga mampu bertahan pada generasi kedua, sementara hanya pada $12 \%$ mampu bertahan pada generasi ketiga dan hanya $3 \%$ yang mampu berkembang sampai generasi keempat (Wahjono, 2009; Susanto, 2005). Terlepas dari permasalahan yang masih dihadapi sampai saat ini, usaha keluarga skala mikro tetap harus dikembangkan. Sasaran pengembangan dapat diarahkan baik untuk peningkatan kapasitas dan kinerja usaha, daya saing, maupun meningkatkan skala usahanya menjadi usaha kecil dan menengah. Untuk mengembangkan usaha diperlukan suatu strategi yang tepat berbasis kondisi faktual baik internal maupun eksternal, agar sasaran pengembangan dapat dicapai secara efektif.

Penelitian tentang pengembangan bisnis UMKM sudah banyak dilakukan diantaranya: Pangestika et al. (2016) meneliti tentang strategi pengembangan UMKM di Kabupaten XYZ; Rahmana et al. (2012) meneliti strategi pengembangan UMKM di Kotamadya Bandung; Utomo (2017) meneliti strategi pengembangan UMKM di Kota Tarakan, serta Hamid dan Susilo (2011) meneliti strategi pengembangan UMKM di Kota Yogyakarta. Keempat penelitian ini meneliti baik usaha mikro, kecil, maupun menengah dengan berbagai bidang usaha. Beberapa hasil dari keempat penelitian tersebut mengarah pada strategi berikut : pengembangan produk dan penetrasi pasar, diversifikasi produk, peningkatan kualitas produk, peningkatan kualitas bahan baku, kualitas SDM, legalitas usaha, strategi harga bersaing, pengembangan produk berdaya saing, revitalisasi mesin dan peralatan, promosi ke pasar ekspor, dan lain-lain. Penelitian lain dilakukan terhadap UMKM dengan hanya satu bidang usaha, misalnya Rumanti dan Syauta (2013) meneliti strategi pengembangan usaha batu alam di Tulung Agung; Purwono et al. (2015) meneliti strategi pengembangan UMKM Tempe di Kota Bogor; Agusetyaningrum et al. (2016) meneliti strategi pengembangan UKM kuliner di Kota Malang; Pengemanan dan Walukow (2018) meneliti strategi pemasaran UMKM industri mebel di Minahasa; serta Alyas dan Rakib (2017) meneliti strategi pengembangan UMKM Roti di Kabupaten Maros. Kelima penelitian ini memberikan rekomendasi strategi dengan arah yang relatif sama.

Berdasarkan fenomena di atas, penelitian ini fokus untuk menganalisis strategi pengembangan terhadap usaha keluarga skala mikro bidang kuliner yang ada di Kota Palembang. Perbedaan penelitian ini dengan penelitian terdahulu terletak pada fokus penelitian yang lebih spesifik. Penelitian ini hanya meneliti usaha skala mikro yang dimiliki oleh keluarga (bisnis keluarga) dan hanya bergerak dalam satu bidang usaha yaitu usaha kuliner. Tujuan yang ingin dicapai dalam penelitian ini adalah untuk mengetahui karakteristik usaha keluarga dari sisi pengelolaan dan skala usaha mikro, faktor strategis internal (kekuatan dan kelemahan) dan eksternal (peluang dan ancaman) dari usaha keluarga, menganalisis berbagai alternatif strategis yang akan dipilih sebagai strategi pengembangan usaha keluarga, kemudian menentukan strategi utama yang dapat diimplementasikan. 


\section{METODE}

Penelitian ini merupakan penelitian deskriptif, bertujuan untuk memperoleh penjelasan secara umum dan menyeluruh tentang kondisi sebenarnya melalui pengumpulan dan interpretasi data-data yang diperoleh (Kriyantono, 2007), analisis fakta, sifat maupun hubungan antara fenomena yang sedang diselidiki (Sugiyono, 2017). Objek yang diteliti adalah usaha keluarga skala mikro di Kota Palembang. Pemilihan sampel menggunakan teknik sampling purposive dan convenience, dengan kriteria antara lain: Usaha merupakan usaha skala mikro dengan pertimbangan usaha yang paling banyak mengalami kendala dalam pengelolaannya (Kuncoro, 2013); dimiliki/dikelola oleh keluarga dan bergerak dalam bidang kuliner; usaha merupakan milik mahasiswa dan keluarga mahasiswa STIE MDP. Berdasarkan pertimbangan tersebut dipilih sebagai unit analisisnya adalah 43 usaha keluarga dengan pemilik/pengelola usaha sebagai responden penelitian.

Data yang digunakan yaitu data primer dan sekunder. Data primer merupakan informasi yang diperoleh dari pemilik/pengelola usaha keluarga yang menjadi objek penelitian, meliputi informasi tentang profil pemilik/pengelola usaha, karakteristik dan perkembangan usaha, manajemen usaha, kondisi internal usaha, rencana pengembangan dan suksesi dalam pengelolaan usaha pada masa yang akan datang. Data ini dikumpulkan dengan menyebarkan kuesioner, wawancara, dan observasi. Data sekunder adalah data karakteristik umum tentang usaha keluarga dan usaha mikro di Indonesia, kondisi eksternal terkait usaha responden, serta pengelolaan usaha mikro milik keluarga yang diperoleh melalui studi literatur.

Dalam penelitian ini data akan dianalisis secara deskriptif, yaitu memberikan gambaran pola-pola yang konsisten dalam data, sehingga hasilnya dapat dipelajari dan ditafsirkan secara singkat dan penuh makna (Kuncoro, 2009). Agar hasil analisis data dapat dipahami secara kuantitatif, maka analisis dilengkapi dengan analisis statistik sederhana berupa tabulasi frekuensi. Dalam analisis data, tidak saja dilakukan interpretasi terhadap data dan hubungan yang ada, tetapi juga dilakukan komparasi dengan hasil penelitian sejenis (Singarimbun \& Effendi, 2007).

Analisis dilakukan secara bertahap. Tahap pertama, dilakukan analisis kondisi faktual internal dan eksternal menggunakan analisis matriks IFE (internal factors evaluation) dan EFE (external factor evaluation). Analisis ini bertujuan untuk mengetahui faktor strategis internal dan eksternal dari usaha keluarga. Tahap kedua, dilakukan perumusan alternatif strategi menggunakan analisis Matriks SWOT untuk mengetahui alternatif strategi yang akan dipilih yang berasal dari empat kombinasi strategi (SO, ST, WO, WT). Tahap ketiga, dilakukan analisis penilaian terhadap berbagai alternatif strategi dengan menghitung skor masing-masing kombinasi strategi SWOT, sehingga akan diperoleh strategi terbaik dan prioritas yang akan diimplementasikan oleh pelaku usaha. (David, 2015; David et al., 2017; Gupta et al., 2015; Alyas \& Rakib, 2017; Rahmana et al., 2012). Tahapan penelitian digambarkan dalam bentuk fishbone diagram sebagai berikut:

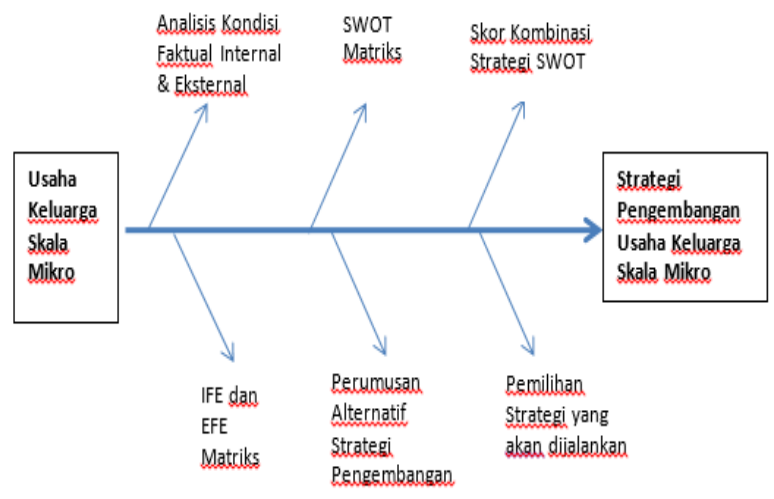

Gambar 1. Tahapan Penelitian

\section{HASIL DAN PEMBAHASAN Karakteristik Demografi Responden}

Karakteristik demografi responden berdasarkan usia, jenis kelamin, dan tingkat pendidikan disajikan dalam Tabel 1 . 
Tabel 1. Karakteristik Demografi

\begin{tabular}{lrr}
\hline \multicolumn{1}{c}{ Karakteristik } & Frekuensi & $\%$ \\
\hline Usia (thn): & 7 & 16,28 \\
$20-30$ & 10 & 23,26 \\
$31-40$ & 15 & 34,88 \\
$41-50$ & 11 & 25,58 \\
$51-60$ & & \\
Jenis kelamin & 22 & 51,16 \\
Laki-laki & 21 & 48,84 \\
Perempuan & & \\
Tingkat Pendidikan & 1 & 2,32 \\
SD & 5 & 11,63 \\
SLTP & 27 & 62,79 \\
SLTA & & \\
Diploma & 10 & 23,26 \\
Sarjana & & 100,00 \\
& 43 &
\end{tabular}

Sumber: Hasil penelitian, tahun 2020

Jika dilihat dari karakteristik usia, menunjukkan bahwa pemilik (pengelola) usaha terkonsentrasi pada usia 30-60 tahun dan hal ini selaras dengan karakteristik usaha dimana pemilik (pengelola) usaha saat ini sebagian besar merupakan generasi pertama. Dari karakteristik jenis kelamin, diperoleh jumlah yang seimbang antara laki-laki dan perempuan. Hal ini menunjukkan bahwa perempuan memiliki kesempatan yang sama dengan laki-laki untuk memimpin usaha keluarga, khususnya usaha kuliner rumahan. Sedangkan dari karakteristik tingkat pendidikan responden, menunjukkan bahwa pemilik usaha dominan berpendidikan SLTA. Hal ini menunjukkan bahwa sebagian besar usaha keluarga didirikan setelah pendiri menamatkan pendidikan SLTA. Waktu yang tersita untuk menjalankan usaha menyebabkan tidak adanya keinginan untuk melanjutkan pendidikan ke jenjang yang lebih tinggi.

\section{Karakteristik Usaha}

Karakteristik dari aspek pengelolaan usaha keluarga, disajikan dalam Tabel 2 berikut:

Tabel 2. Karakteristik Usaha Keluarga

\begin{tabular}{rlllrr}
\hline No & Aspek & & Keterangan & Frek & $\%$ \\
\hline 1 & Legalitas & Badan & $\bullet$ Ada & 3 & 6,98 \\
& usaha & Hukum & $\bullet$ Belum ada & 40 & 93,02 \\
& & Izin & $\bullet$ Ada & 34 & 79,07 \\
& & Usaha & $\bullet$ Belum ada & 9 & 20,93
\end{tabular}

\begin{tabular}{|c|c|c|c|c|c|}
\hline No & Aspek & & Keterangan & Frek & $\%$ \\
\hline \multirow[t]{9}{*}{2} & \multirow{9}{*}{$\begin{array}{l}\text { Kinerja } \\
\text { usaha }\end{array}$} & Jumlah & - 10-20 juta & 15 & 34,89 \\
\hline & & Aset & - 21-30 juta & 17 & 39,53 \\
\hline & & & - $31-50$ juta & 11 & 25,58 \\
\hline & & & - > 50 juta & 0 & 0 \\
\hline & & Jumlah & $\bullet<10$ juta & 17 & 39,53 \\
\hline & & Omset & - 11-55 juta & 15 & 34,89 \\
\hline & & & - 51-100 juta & 7 & 16,28 \\
\hline & & & - $101-300$ juta & 4 & 9,3 \\
\hline & & & - > 300 juta & 0 & \\
\hline \multirow[t]{16}{*}{3} & \multirow{16}{*}{$\begin{array}{l}\text { Produk \& } \\
\text { Pemasaran }\end{array}$} & Kualitas & - Baik & 26 & 60,47 \\
\hline & & produk & - Kurang baik & 17 & 39,53 \\
\hline & & Varian & - Cukup & 30 & 69,77 \\
\hline & & produk & $\begin{array}{l}\text { bervariasi } \\
\text { - Kurang } \\
\text { bervariasi }\end{array}$ & 13 & 30,23 \\
\hline & & Bahan & - Mudah & 41 & 95,35 \\
\hline & & baku & $\begin{array}{l}\text { diperoleh } \\
\text { - Sulit } \\
\text { diperoleh }\end{array}$ & 2 & 4,65 \\
\hline & & Kemasan & - Cukup & 14 & 32,56 \\
\hline & & & $\begin{array}{l}\text { menarik } \\
\text { - Kurang } \\
\text { menarik }\end{array}$ & 29 & 67,44 \\
\hline & & Merek & • Cukup & 13 & 30,23 \\
\hline & & & dikenal & 16 & 37,21 \\
\hline & & & $\begin{array}{l}\text { - Kurang } \\
\text { dikenal } \\
\text { - Belum ada }\end{array}$ & 14 & 32,56 \\
\hline & & Media & - Word of & 22 & 51,16 \\
\hline & & promosi & Mouth & & 18,61 \\
\hline & & & • Brosur & 8 & 0 \\
\hline & & & - Surat kabar & 0 & 30,23 \\
\hline & & & - Media Sosia & 13 & \\
\hline \multirow[t]{7}{*}{4} & \multirow{7}{*}{$\begin{array}{l}\text { Manajemen } \\
\text { usaha }\end{array}$} & Generasi & - Pertama & 36 & 83,72 \\
\hline & & & - Kedua & 8 & 18,61 \\
\hline & & & - Ketiga & 0 & 0 \\
\hline & & Rencana & - Ada & 0 & 0 \\
\hline & & Suksesi & - Belum ada & 43 & 100 \\
\hline & & Tenaga & - Ada & 5 & 11,63 \\
\hline & & $\begin{array}{l}\text { Profesio- } \\
\text { nal }\end{array}$ & - Belum ada & 38 & 88,37 \\
\hline \multirow[t]{11}{*}{5} & \multirow{11}{*}{$\begin{array}{l}\text { Tenaga } \\
\text { Kerja }\end{array}$} & Jumlah & - $1-2$ orang & 21 & 48,84 \\
\hline & & Tenaga & - 3-4 orang & 7 & 16,28 \\
\hline & & Kerja & - > 4 orang & 15 & 34,88 \\
\hline & & Kualitas & - Terampil & 10 & 23,26 \\
\hline & & $\begin{array}{l}\text { tenaga } \\
\text { kerja }\end{array}$ & $\begin{array}{l}\text { - Tidak } \\
\text { terampil }\end{array}$ & 33 & 76,74 \\
\hline & & Menerima & - Pernah & 6 & 13,95 \\
\hline & & Pelatihan & $\begin{array}{l}\text { - Belum } \\
\text { pernah }\end{array}$ & 37 & 86,05 \\
\hline & & Pendidik- & - SD & - & \\
\hline & & an & - SLTP & 4 & 9,30 \\
\hline & & & • SLTA & 34 & 79,07 \\
\hline & & & $\begin{array}{l}\text { - Diploma/ } \\
\text { Sarjana }\end{array}$ & 5 & 11,63 \\
\hline \multirow[t]{6}{*}{6} & \multirow{6}{*}{$\begin{array}{l}\text { Pengelolaan } \\
\text { Keuangan/ } \\
\text { Modal }\end{array}$} & Sumber & - Modal & 39 & 90,70 \\
\hline & & Modal & sendiri & 0 & 0 \\
\hline & & & $\begin{array}{l}\text { - Lembaga } \\
\text { keuangan }\end{array}$ & 4 & 9,30 \\
\hline & & & $\begin{array}{l}\text { - Famili/ } \\
\text { saudara }\end{array}$ & & \\
\hline & & Menerima & - Pernah & 11 & 25,58 \\
\hline & & Bantuan & - Belum & 33 & 76,75 \\
\hline
\end{tabular}




\begin{tabular}{lllrr}
\hline No Aspek & & Keterangan & Frek & $\%$ \\
\hline & Modal & pernah & & \\
& Adminis- & $\bullet$ Catatan & 33 & 76,74 \\
& trasi & sederhana & 6 & 13,96 \\
& Keuangan & $\bullet$ L/R- & 4 & 9,30 \\
& & Necara & & \\
& & $\bullet$ Belum ada & & \\
& Uang & $\bullet$ Terpisah & 7 & 16,28 \\
& usaha \& & $\bullet$ Belum & 36 & 3,72 \\
& keluarga & Terpisah & & \\
& $\begin{array}{l}\text { Meng- } \\
\text { ajukan } \\
\text { pinjaman } \\
\text { bank }\end{array}$ & $\bullet$ Pernah & 4 & 9,30 \\
& pelum & 39 & 90,70 \\
& & & \\
\hline
\end{tabular}

Sumber: hasil penelitian, tahun 2020

Dari Tabel 2 diperoleh indikasi bahwa usaha keluarga yang menjadi objek penelitian tergolong dalam usaha skala mikro dengan karakteristik dominan : belum memiliki badan hukum, izin usaha hanya berbentuk izin gangguan, jumlah asset maksimal Rp50.000.000,00 jumlah omset maksimal Rp300.000.000,00 mengandalkan modal sendiri, minimnya akses pinjaman bank, administrasi keuangan masih sederhana, dan tenaga kerja sebagian besar termasuk tidak terampil, berpendidikan SLTA, serta belum banyak yang mendapat pelatihan.

Selain itu kinerja pemasaran belum terlaksana dengan baik, seperti kemasan kurang menarik, merek kurang dikenal dan bahkan ada yang belum memiliki merek, sebagian besar hanya menggunakan WOM dan belum banyak yang menggunakan media sosial. Dari sisi karaketristik usaha keluarga, sebagian besar usaha dimiliki dan dikelola oleh generasi pertama, belum memiliki rencana suksesi, sebagian besar belum memiliki tenaga profesional, dan keuangan usaha sebagian besar belum dipisahkan dengan keuangan keluarga.

\section{Faktor Strategis Internal (Kekuatan dan Kelemahan) dan Eksternal (Peluang dan Ancaman) dari Usaha Keluarga.}

UMKM di Indonesia, khususnya usaha mikro masih menghadapi berbagai kendala dan kelemahan. Oleh karena itu perlu dilakukan pengembangan dengan strategi yang tepat dan sesuai dengan kondisi maupun karakteristik usahanya. Strategi merupakan alat dan tindakan potensial untuk mencapai tujuan jangka panjang dan membutuhkan keputusan manajemen puncak dan sumber daya perusahaan (David, 2009). Agar diperoleh strategi yang tepat, perlu dilakukan tiga tahap yaitu formulasi strategi, implementasi strategi, dan evaluasi strategi.

Strategi pengembangan UMKM dilakukan melalui tiga tahap yaitu analisis kondisi faktual internal dan eksternal, formulasi alternatif strategi, dan pemilihan strategi terbaik dan prioritas yang akan diimplementasikan sesuai dengan kebutuhan dan kemampuan UMKM. Kondisi internal dan eksternal dianalisis menggunakan Matriks IFE (Internal Factors Evaluation) dan EFE (external factors evaluation) (Alyas \& Rakib, 2017; Pengemanan, \& Walukow, 2018; Agusetyaningrum et al., 2016; Purwono et al., 2015; Rumanti \& Syauta, 2013; Utomo, 2017; Pangestika et al., 2016; Rahmana et al., 2012; Hamid \& Susilo, 2011; Anggraeni et al., 2017)

Matriks IFE adalah matriks yang digunakan untuk mengevaluasi faktor internal yang terdiri kekuatan dan kelemahan yang terdapat pada seluruh divisi dalam perusahaan. Sedangkan Matriks EFE digunakan untuk mengevaluasi faktor eksternal perusahaan yang meliputi peluang dan ancaman yang memperngaruhi perusahaan. Faktor eksternal tersebut meliputi faktor ekonomi, sosial, budaya, demografi, lingkungan, politik, pemerintah, hukum, teknologi, dan persaingan.

Formulasi strategi dilakukan dengan menggunakan Matriks SWOT (strangeths, weaknesses, opportunities, threats), kemudian untuk memperoleh alternatif strategi terlebih dahulu dilakukan analisis melalui diagram kartesius SWOT agar dapat diketahui posisi strategi perusahaan. Selanjutnya alternatif strategi diperoleh melalui analisis matrik SWOT yang digunakan untuk mencocokkan empat faktor SWOT agar diperoleh empat strategi: (strengths- opportunities-SO), (weaknessesopportunities-WO), (weaknesses-threats$W T$ ), dan (strengths-threats-ST). Tahap akhir adalah menentukan nilai kombinasi strategi 
SWOT untuk mengetahui strategi pengembangan yang paling utama dan prioritas untuk diimplementasikan. Hasil identifikasi SWOT dan penentuan Faktor Strategis Internal dan Eksternal disajikan pada Tabel 3, Tabel 4, dan Tabel 5.

Tabel 3. Strength-Weakness-Opportunity-Threat Model (SWOT)

\begin{tabular}{|c|c|}
\hline STRENGTH (S) & WEAKNESS (W) \\
\hline S1 Hubungan dengan & W1 Adminitrasi \\
\hline karyawan sudah baik & keuangan belum \\
\hline S2 Harga produk terjangka & baik \\
\hline $\begin{array}{l}\text { S3 Hubungan dengan } \\
\text { pemasok \& reseler baik }\end{array}$ & $\begin{array}{l}\text { W2 Inovasi produk } \\
\text { masih kurang }\end{array}$ \\
\hline $\begin{array}{l}\text { S4 Hubungan baik dengan } \\
\text { pelanggan }\end{array}$ & $\begin{array}{l}\text { W3 Promosi belum } \\
\text { optimal }\end{array}$ \\
\hline $\begin{array}{l}\text { S5 Ikatan emosi antara } \\
\text { anggota keluarga }\end{array}$ & $\begin{array}{l}\text { W4 Merek belum } \\
\text { dikenal }\end{array}$ \\
\hline $\begin{array}{l}\text { S6 Kualitas produk sudah } \\
\text { cukup baik }\end{array}$ & $\begin{array}{l}\text { W5 Modal usaha } \\
\text { terbatas (modal }\end{array}$ \\
\hline $\begin{array}{l}\text { S7 Motivasi \& komitmen } \\
\text { anggota keluarga kuat }\end{array}$ & $\begin{array}{l}\text { sendiri) } \\
\text { W6 Pemasaran }\end{array}$ \\
\hline S8 Saling percaya dan & \\
\hline $\begin{array}{l}\text { kerjasama yang tinggi } \\
\text { S9 Usaha turun menurun }\end{array}$ & $\begin{array}{l}\text { W7 Belum memiliki } \\
\text { izin usaha }\end{array}$ \\
\hline OPPORTUNITY (OP) & THREAT $(\mathrm{T})$ \\
\hline $\begin{array}{l}\text { O1 Dukungan dinas } \\
\text { perindustrian, } \\
\text { perdagangan, dan } \\
\text { koperasi \& UKM } \\
\text { Kota Palembang }\end{array}$ & $\begin{array}{l}\text { T1 Berubahnya selera } \\
\text { konsumen } \\
\text { T2 Daya beli } \\
\text { masyarakat } \\
\text { cenderung menurun }\end{array}$ \\
\hline $\begin{array}{l}\text { O2 Hubungan baik } \\
\text { dengan pelanggan }\end{array}$ & $\begin{array}{l}\text { T3 Harga bahan baku } \\
\text { cenderung }\end{array}$ \\
\hline O3 Kebijakan & meningkat \\
\hline $\begin{array}{l}\text { pemerintah tentang } \\
\text { UMKM }\end{array}$ & $\begin{array}{c}\text { T4 Ketersediaan bahan } \\
\text { baku yang makin }\end{array}$ \\
\hline O4 Perkembangan & sulit \\
\hline Teknologi Informasi & T5 Menurunnya minat \\
\hline O5 Tersedianya fasilitas & konsumen \\
\hline kredit UMKM & T6 Persaingan yang \\
\hline O6 Terbukanya & makin tajam \\
\hline $\begin{array}{l}\text { kerjasama dengan } \\
\text { perguruan tinggi } \\
\text { dan BUMN/swasta. }\end{array}$ & $\begin{array}{l}\text { T7 Halangan syarat \& } \\
\text { prosedur } \\
\text { mengakses kredit } \\
\text { bank }\end{array}$ \\
\hline
\end{tabular}

Tabel 4. Internal Factor Evaluation Matrix (IFEM)

\begin{tabular}{lccc}
\hline Internal Factors & Weight & Rating & $\begin{array}{c}\text { Weighted } \\
\text { Score }\end{array}$ \\
\hline $\begin{array}{l}\text { STRENGTHS (S) } \\
\text { S1 Hubungan } \\
\quad \text { dengan } \\
\quad \text { karyawan } \\
\quad \text { sudah baik }\end{array}$ & 0,02 & 1 & 0,02 \\
$\begin{array}{l}\text { S2 Harga produk } \\
\text { argat }\end{array}$ & 0,03 & 2 & 0,06
\end{tabular}

\begin{tabular}{|c|c|c|c|}
\hline Internal Factors & Weight & Rating & $\begin{array}{c}\text { Weighted } \\
\text { Score }\end{array}$ \\
\hline terjangkau & & & \\
\hline $\begin{array}{l}\text { S3 Hubungan } \\
\text { dengan } \\
\text { pemasok \& } \\
\text { reseler baik }\end{array}$ & 0,04 & 2 & 0,08 \\
\hline $\begin{array}{l}\text { S4 Hubungan } \\
\text { baik dengan } \\
\text { pelanggan }\end{array}$ & 0,08 & 3 & 0,24 \\
\hline $\begin{array}{l}\text { S5 Ikatan } \\
\text { emosional yan } \\
\text { kuat antara } \\
\text { anggota } \\
\text { keluarga }\end{array}$ & 0,08 & 3 & 0,24 \\
\hline $\begin{array}{l}\text { S6 Kualitas produ } \\
\text { sudah cukup } \\
\text { baik }\end{array}$ & 0,06 & 3 & 0,18 \\
\hline $\begin{array}{l}\text { S7 Motivasi dan } \\
\text { komitmen } \\
\text { anggota } \\
\text { keluarga kuat }\end{array}$ & 0,09 & 4 & 0,36 \\
\hline $\begin{array}{l}\text { S8 Saling percaya } \\
\text { dan kerjasama } \\
\text { yang tinggi }\end{array}$ & 0,08 & 3 & 0,24 \\
\hline $\begin{array}{l}\text { S9 Usaha turun } \\
\text { menurun }\end{array}$ & 0,08 & 3 & 0,24 \\
\hline $\begin{array}{c}\text { Sub total } \\
\text { WEAKNESS (W) }\end{array}$ & 0,56 & & 1,66 \\
\hline $\begin{array}{l}\text { W1 Adminitrasi } \\
\text { keuangan } \\
\text { belum baik }\end{array}$ & 0,06 & 2 & 0,12 \\
\hline $\begin{array}{l}\text { W2 Inovasi produ } \\
\text { masih kurang }\end{array}$ & 0,07 & 1 & 0,07 \\
\hline $\begin{array}{l}\text { W3 Promosi belur } \\
\text { optimal }\end{array}$ & 0,06 & 2 & 0,12 \\
\hline $\begin{array}{l}\text { W4 Merek belum } \\
\text { dikenal }\end{array}$ & 0,06 & 2 & 0,12 \\
\hline $\begin{array}{l}\text { W5 Modal usaha } \\
\text { terbatas } \\
\text { (mengandalka } \\
\text { modal sendiri) }\end{array}$ & 0,09 & 1 & 0,09 \\
\hline $\begin{array}{l}\text { W6 Pemasaran } \\
\text { online belum } \\
\text { optimal }\end{array}$ & 0,06 & 2 & 0,12 \\
\hline $\begin{array}{l}\text { W7 Belum } \\
\text { memiliki } \\
\text { izin usaha }\end{array}$ & 0,06 & 2 & 0,12 \\
\hline Sub total & 0,41 & & 0,76 \\
\hline TOTAL & 1,00 & 2,42 & \\
\hline
\end{tabular}

Tabel 4 menyajikan nilai faktor internal (kekuatan-kelemahan) usaha keluarga yang akan dikembangkan. Dari hasil evaluasi faktor internal diperoleh nilai tertinggi untuk kekuatan adalah motivasi dan komitmen anggota keluarga yang kuat $(0,36)$ diikuti oleh saling percaya dan kerjasama 
yang tinggi $(0,24)$, usaha turun temurun $(0,24)$, hubungan baik dengan pelanggan $(0,24)$ dan ikatan emosional yang kuat antara keluarga $(0,24)$. Dapat dikatakan bahwa dukungan faktor keluarga merupakan kekuatan usaha untuk dikembangkan lebih lanjut. Sedangkan untuk kelemahan diperoleh nilai tertinggi adalah $(0,12)$ yaitu adanya kelemahan dalam hal administrasi keuangan, promosi usaha, merek, pemasaran online, dan izin usaha. Bila ingin mengembangkan usaha ini maka kelemahan tersebut harus dibenahi terlebih dahulu. Kekuatan memberikan indikasi adanya kemungkinan strategi yang akan berhasil, sedangkan kelemahan menunjukkan masih adanya hal-hal yang harus diperbaiki (Kotler \& Amstrong, 2013)

Tabel 5. External Factor Evaluation Matrix (EFEM)

\begin{tabular}{|c|c|c|c|}
\hline External Factors & Weight & Rating & $\begin{array}{l}\text { Weight } \\
\text { Scre }\end{array}$ \\
\hline \multicolumn{4}{|l|}{ OPPORTUNITIES (O) } \\
\hline $\begin{array}{l}\text { O1 Dukungan dinas } \\
\text { perindustrian, } \\
\text { perdagangan, dan } \\
\text { koperasi \& UKM } \\
\text { Kota Palembang }\end{array}$ & 0,08 & 4 & 0,32 \\
\hline $\begin{array}{l}\text { O2 Hubungan baik } \\
\text { dengan pelanggan }\end{array}$ & 0,09 & 3 & 0,27 \\
\hline $\begin{array}{l}\text { O3 Kebijakan } \\
\text { pemerintah } \\
\text { tentang UMKM }\end{array}$ & 0,06 & 3 & 0,18 \\
\hline $\begin{array}{l}\text { O4 Perkembang-an } \\
\text { Teknologi } \\
\text { Informasi }\end{array}$ & 0,13 & 3 & 0,36 \\
\hline $\begin{array}{l}\text { O5 Tersedianya } \\
\text { fasilitas kredit } \\
\text { UMKM }\end{array}$ & 0,11 & 4 & 0,44 \\
\hline $\begin{array}{l}\text { O6 Terbukanya } \\
\text { kerjasama dengan } \\
\text { perguruan tinggi, } \\
\text { BUMN/ Swasta }\end{array}$ & 0,09 & 3 & 0,27 \\
\hline $\begin{array}{l}\text { Sub Total } \\
\text { THREATS }(\mathrm{T})\end{array}$ & 0,56 & & 1,84 \\
\hline $\begin{array}{l}\text { T1 Berubahnya selera } \\
\text { konsumen }\end{array}$ & 0,06 & 3 & 0,18 \\
\hline $\begin{array}{l}\text { T2 Daya beli } \\
\text { masyarakat } \\
\text { cenderung } \\
\text { menurun }\end{array}$ & 0,06 & 2 & 0,12 \\
\hline $\begin{array}{l}\text { T3 Harga bahan baku } \\
\text { cenderung } \\
\text { meningkat }\end{array}$ & 0,04 & 2 & 0,08 \\
\hline T4 Ketersediaan & 0,05 & 2 & 0,10 \\
\hline
\end{tabular}

\begin{tabular}{cccc}
\hline External Factors & Weight & Rating & $\begin{array}{c}\text { Weight } \\
\text { Scre }\end{array}$ \\
\hline $\begin{array}{l}\text { bahan baku yang } \\
\text { makin sulit }\end{array}$ & & & \\
$\begin{array}{l}\text { T5 Menurunnya } \\
\text { minat konsumen }\end{array}$ & 0,07 & 2 & 0,14 \\
$\begin{array}{c}\text { T6 Persaingan yang } \\
\text { makin tajam }\end{array}$ & 0,09 & 1 & 0,09 \\
$\begin{array}{c}\text { T7 Halangan syarat } \\
\text { dan prosedur } \\
\text { mengakses kredit }\end{array}$ & 0,07 & 1 & 0,07 \\
$\quad$ bank Sub Total & 0,44 & & \\
$\quad$ TOTAL & 1,00 & & $\mathbf{0 , 7 8}$ \\
& & & 2,62 \\
\hline
\end{tabular}

Tabel 5 menyajikan nilai faktor eksternal (peluang-ancaman) usaha keluarga yang akan dikembangkan. Dari hasil evaluasi faktor eksternal diperoleh nilai tertinggi yaitu tersedianya fasilitas kredit UMKM $(0,44)$, diikuti oleh perkembangan teknologi informasi $(0,36)$, dukungan dari dinas terkait $(0,32)$, hubungan baik dengan pelanggan $(0,27)$, dan terbukanya kerjasama dengan perguruan tinggi-BUMN/Swasta $(0,27)$. Sedangkan dari sisi ancaman, berubahnya selera konsumen $(0,18)$ menjadi ancaman utama dan diikuti oleh menurunnya minat konsumen $(0,14)$, serta daya beli masyarakat yang cenderung menurun $(0,12)$. Hal ini menunjukkan bahwa sangat terbuka luas peluang untuk mengembangkan usaha. Namun ancaman yang dihadapi harus dihadapi dengan strategi yang tepat.

\section{Strategi Pengembangan Usaha Keluarga}

Untuk memperoleh alternatif strategi pengembangan usaha keluarga, diketahui terlebih dahulu arah atau posisi strategi pengembangannya. Menentukan arah/posisi strategi tersebut menggunakan diagram kartesius SWOT (Alyas \& Rakib, 2017; Rahmana et al., 2012). Untuk menggambarkan diagram tersebut digunakan nilai skor yang diperoleh dari Matriks Faktor Internal dan Eksternal yaitu skor faktor kekuatan dan kelemahan, serta skor peluang dan ancaman. Dari Tabel 4 diperoleh nilai skor faktor kekuatan 1,66 dan faktor kelemahan 0,76. Selisih antara kedua nilai skor adalah $(+0,90)$. Sedangkan dari Tabel 5 diperoleh nilai skor faktor peluang 1,84 dan 
faktor ancaman 0,78. Selisih antara kedua nilai skor adalah $(+1,06)$.

Dengan menggunakan nilai skor faktor kekuatan, kelemahan, peluang, dan ancaman, serta nilai selisih skor, dapat digambarkan diagram kartesius SWOT seperti yang disajikan pada gambar 1. Nilai skor kekuatan dan peluang diberi nilai positif (+), sedangkan nilai skor kelemahan dan ancaman diberi nilai negatif (-).

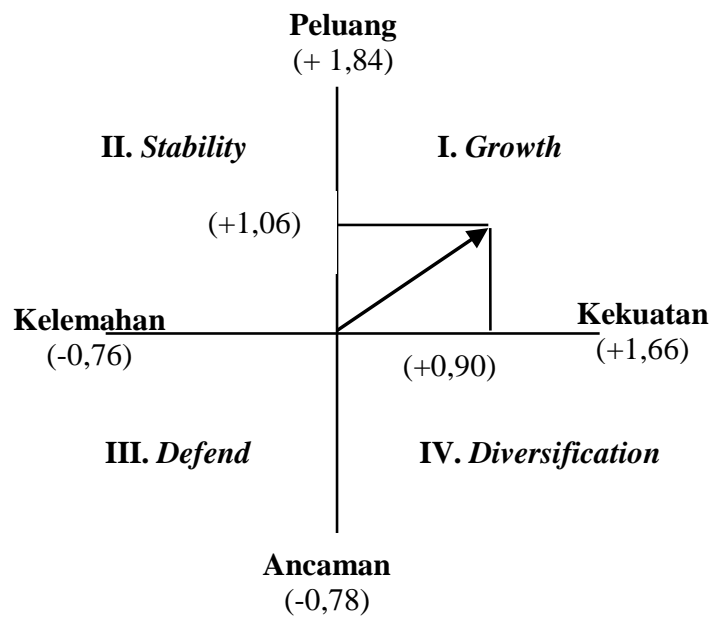

Gambar 2. Diagram Kartesius SWOT

Berdasarkan analisis diagram kartesius pada Gambar 2, terlihat bahwa posisi usaha keluarga yang diteliti berada pada posisi kuadran I yaitu Growth, sehingga strategi yang tepat adalah strategi pertumbuhan. Menurut Coulter (2002) dalam Kuncoro (2006) Strategi pertumbuhan adalah strategi bagaimana menggerakkan organisasi perusahaan ke depan. Dalam hal ini perusahaan berharap dapat meningkatkan level operasinya agar tumbuh lebih cepat. Perusahaan mengembangkan bisnis dengan konsentrasi pada bisnis saat ini dan perluasan pasar melalui peningkatan kualitas produk, inovasi produk, peningkatan penjualan produk dengan kegiatan atau media promosi baru, mempertahankan dan meningkatkan pelanggan, serta melakukan berbagai kerjasama dengan pihak eksternal.

\section{Penentuan Alternatif Strategi}

Untuk memperoleh berbagai alternatif strategi pengembangan usaha keluarga dilakukan analisis SWOT (strengthweakness-opportunity-threat). Dari hasil matrik SWOT yang disajikan pada Tabel 6 diperoleh beberapa alternatif strategi yaitu SO Strategies (3 strategi), WO strategies (4 strategi), ST strategies (2 strategi), dan WT strategies (2 strategi).

Tabel 6. Strength-Weakness-Opportunity-Threat (SWOT) Matrix

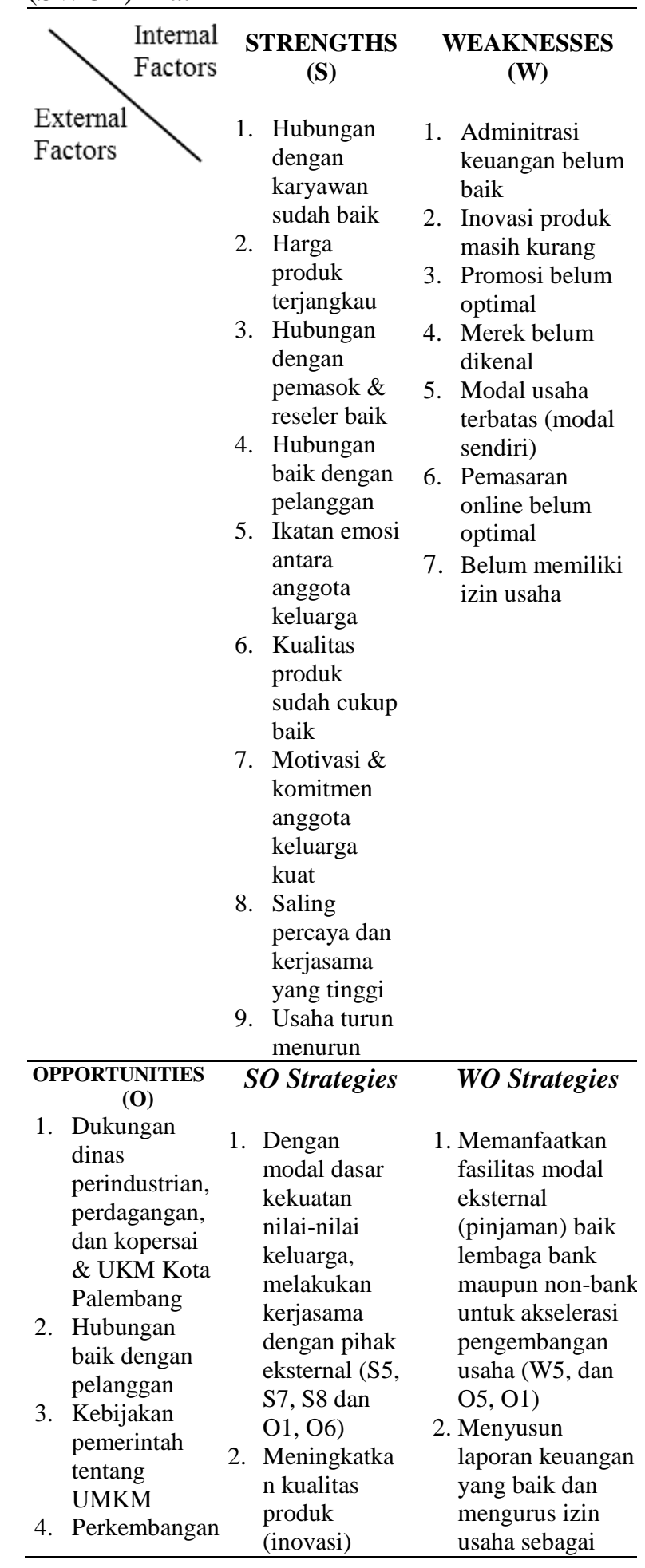




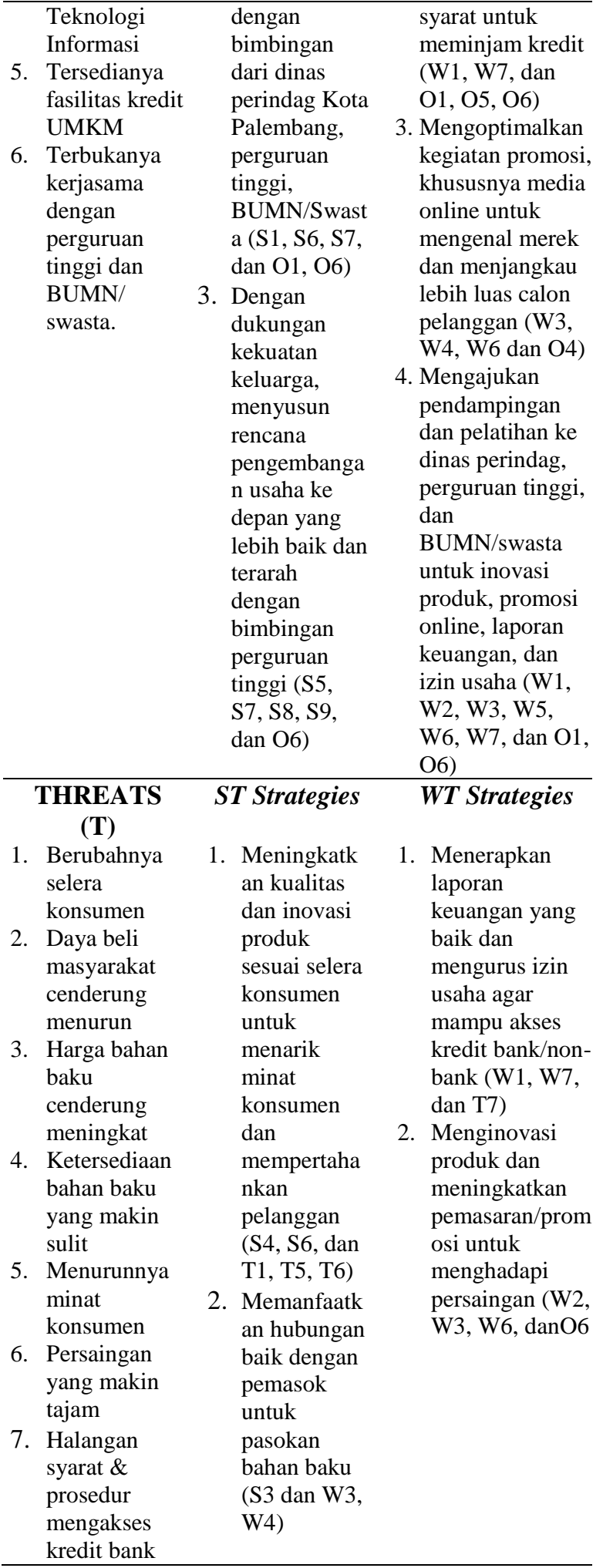

\section{Strategi Prioritas dan Implementasi Pengembangan Usaha Keluarga}

Untuk menentukan alternatif strategi yang menjadi prioritas untuk dilaksanakan adalah dengan mengetahui total nilai skor masing-masing kombinasi strategi SWOT yang terdapat pada matriks faktor internal dan eksternal (Tabel 4 dan 5). Total skor masing-masing alternatif strategi adalah sebagai berikut:

Tabel 7. Nilai Skor Kombinasi Strategi SWOT

\begin{tabular}{cll}
\hline \multirow{2}{*}{ EFEM } & \multicolumn{2}{c}{ IFEM } \\
\cline { 2 - 3 } & $\begin{array}{c}\text { Kekuatan } \\
\text { (Strength-S) }\end{array}$ & $\begin{array}{c}\text { Kelemahan } \\
(\text { Weakness-W) }\end{array}$ \\
\hline Peluang & Strategi SO & Strategi WO = \\
(Opportunity-O) & $=1,66+$ & $0,76+1,84=$ \\
& $1,84=3,50$ & 2,60 \\
Ancaman & Strategi ST & Strategi WT \\
(Threat-T) & $=1,66+$ & $=0,76+0,78=$ \\
& $0,78=2,44$ & 1,54 \\
\hline
\end{tabular}

Berdasarkan nilai skor kombinasi strategi SWOT pada Tabel 7 di atas, diperoleh nilai skor tertinggi adalah strategi SO $(3,50)$ diikuti oleh strategi WO $(2,60)$, strategi ST $(2,44)$ dan strategi WT $(1,54)$. Dari hasil skor tersebut, memberikan indikasi bahwa alternatif strategi pengembangan usaha dari usaha keluarga yang diteliti, terfokus pada alternatif strategi SO dan WO, diikuti oleh strategi ST dan WT. Strategi SO merupakan strategi yang mendasar dan sifatnya untuk jangka panjang, sedangkan strategi WO merupakan strategi operasional yang bersifat relatif jangka pendek.

Implementasi strategi SO dan WO didukung oleh strategi ST dan WT dapat dilakukan dalam bentuk kegiatan sebagai berikut:

1. Menyusun rencana pengembangan usaha keluarga dalam jangka panjang yang didukung oleh kekuatan nilai-nilai keluarga. Rencana idealnya bersifat komprehensif dan berkesinambungan dan mengarah kepada peningkatan skala usaha mikro menjadi kecil. Menurut Marpa (2018) perusahaan keluarga harus memiliki rencana strategis bisnis untuk masa depan agar terjamin keberlangsungan usaha. Penyusunan rencana pengembangan usaha dapat dilakukan melalui kerjasama dengan perguruan tinggi yang ada di Kota Palembang.

2. Melaksanakan kerjasama dengan pihak eksternal (dinas perindustrian, perdagangan, koperasi \& UKM, 
perguruan tinggi, BUMN dan perusahaan swasta) dalam bentuk kegiatan pelatihan, workshop, pendampingan terkait dengan peningkatan kualitas produk, inovasi produk, penyusunan laporan keuangan, pengurusan izin usaha, pemasaran dan promosi online, serta pembuatan proposal pengajuan pinjaman kredit baik ke bank maupun non bank. Berbagai pihak eksternal yang dapat diminta untuk memberikan pelatihan, pendampingan, dan pembinaan antara lain Dinas Perindustrian, Perdagangan, Koperasi dan UKM Kota Palembang, Perguruan Tinggi (PTN dan PTS), BUMN (PT Pertamina, PT PUSRI, PT Angkasa Pura II, PT Bukit Asam, PT Telkom, dan lainlain.

3. Untuk menjaga pasokan bahan baku yang stabil dan sebagai antisipasi kenaikan harga bahan baku, maka strategi ST dapat dilakukan yaitu dengan memelihara dan meningkatkan relasi dengan pemasok yang selama ini sudah terjalin dengan baik. Sedangkan untuk menarik minat konsumen dan mempertahankan pelanggan, dapat dilakukan dengan meningkatkan kualitas dan inovasi produk.

4. Untuk menghadapi persaingan dari usaha sejenis serta halangan persyaratan dan prosedur peminjaman kredit dapat dilakukan strategi WT, yaitu mempersiapkan izin usaha dan laporan keuangan yang baik, serta meningkatkan kegiatan promosi (khususnya promosi online). Media promosi online yang paling efektif untuk UMKM saat ini adalah memanfaatkan Instagram, WA, facebook (Kasih, 2019).

\section{Kesimpulan}

Usaha keluarga yang diteliti memiliki kekuatan dan peluang yang kuat untuk dikembangkan lebih lanjut. Faktor yang menjadi kekuatan utama adalah adanya dukungan yang kuat dari pihak keluarga. Sedangkan peluang yang utama adalah tersedianya fasilitas kredit UMKM, pemanfaatan teknologi informasi (pemasaran online), dan dukungan dari lembaga dinas terkait (perdagangan, dan koperasi-UKM). Kelemahan (administrasi keuangan, promosi usaha, merek, pemasaran online, dan izin usaha) yang masih dialami dan adanya ancaman (berubahnya selera konsumen, menurunnya minat dan daya beli masyarakat) yang dihadapi harus diatasi dengan baik sehingga pengembangan usaha ke depan dapat dilakukan secara efektif.

Usaha keluarga skala mikro yang diteliti berada pada kuadran I pada diagram kartesius SWOT yaitu berada pada posisi strategi pertumbuhan (growth). Dalam hal ini pengembangan usaha dapat dilakukan melalui peningkatan skala bisnis dengan menyusun rencana strategis bisnis; melaksanakan kerjasama dengan pihak eksternal dalam bentuk pelatihan dan pendampingan terkait peningkatan kualitas produk, inovasi produk, penyusunan laporan keuangan, pengurusan izin usaha, pemasaran online (digital marketing), dan penyusunan proposal kredit; membina hubungan dengan pemasok dan mempertahankan hubungan dengan pelanggan yang sudah terbina dengan baik.

Penelitian ini menghasilkan temuan (novelty) yaitu karakteristik keluarga dan yang terbangun dengan kuat di dalam usaha keluarga didukung oleh perbaikan karakteristik usaha mikro yang masih lemah menjadi modal dasar yang kuat bagi perkembangan usaha keluarga khususnya usaha keluarga skala mikro.

\section{DAFTAR PUSTAKA}

Agusetyaningrum, V., Mawardi, M. K. \& Pangestuti, E. (2016). Strategi Pengembangan Usaha Kecil dan Menengah (UKM) Untuk Meningkatkan Citra Kota Malang Sebagai Destinasi Wisata Kuliner (Studi Kasus Pada UKM Berbasis Kuliner Kota Malang), Jurnal Adminitrasi Bisnis (JAB), 38(2), 105111.

Alyas \& Rakib, M. (2017). Strategi Pengembangan Usaha Mikro Kecil dan Menengah Dalam Penguatan Ekonomi 
Kerakyatan (Studi Kasus pada Usaha Roti Maros di Kabupaten Maros), Sosiohumaniora: Jurnal of Social Sciences and Humanities, 19(2), 114120.

Anggraeni, P., Sunarti, \& Mawardi, M. K. (2017). Analisis SWOT Pada UMKM Keripik Tempe Amel Malang Dalam Rangka Meningkatkan Daya Saing Perusahaan. Jurnal Adminitrasi Bisnis (JAB), 43(1), 104-113.

Bank Indonesia. (2015). Profil Bisnis Usaha Mikro Kecil Menengah (UMKM).Online

https://www.bi.go.id/id/umkm/peneliti an/nasional/.../Profil\%20Bisnis\%20U MKM.pdf

Craig, J., Dibrell, C. \& Davis, P. (2008), Leveraging family-based brand indentity to enhance firm competitiveness and performance in family businesses, Journal of Small Business Manaement, 46(3), (351-371.

David, F.R \& David, F.R. (2015). Manajemen Strategik, Suatu Pendekatan Keunggulan Bersaing, Edisi 15, Jakarta: Penerbit Salemba Empat.

David, M.E., David, F.R., \& David, F.R. (2009). The quantitative strategic planning matrix (QSPM) applied to a retail computer store. The Coastal Business Journal, 8(1), 42-52.

David, M.E., David, F.R., \& David, F.R. (2017). The quantitative strategic planning matrix: A new marketing tool, Journal of Strategic Marketing, 25(4), 342-352.

Gupta, M., Shri, C., \& Agrawal, A. (2015). Strategiy formulation for performance improvement of indian corrugated industry: An application of SWOT analysis and QSPM matrix, Journal of Applied Packaging Research, 7(3), 6075.

Hamid, E.S., \& Susilo, Y.R. (2011). Strategi Pengembangan Usaha Mikro Kecil dan Menengah Di Provinsi Daerah Istimewa Yogyakarta, Jurnal Ekonomi Pembangunan, 12(1), 45-55.
Ingalsuo, M. (2014). Challenges and opportunity of family business, Bachelor's Thesis, International Business Management, Turku University of Applied Science, 49.

Kasih, Y. (2019). Sumber-Sumber Pembiayaan UMKM, Palembang: Penerbit Yayasan Multi Data.

Katua, N. T., (2014). The role of SMEs in employment creation and economic growth in selected countries, International Journal of Education and Research, 2(12), 461-472.

Kementerian Koperasi dan UKM, Data Usaha Mikro, Kecil dan Menengah dan Besar Tahun 2005-2013, www.smecda.com

Kementerian Koperasi dan UKM, Penyerapan Tenaga Kerja Pada UMKM Tahun 2005-2013, www.smecda.com

Kementerian Koperasi dan UKM, Kontribusi PDB Pada UMKM Tahun 2005-2013, www.smecda.com

Kotler \& Amstrong (2013). Manajemen Pemasaran. Jakarta: Erlangga

Kriyantono, R. (2007). Teknik Praktis Riset Komunikasi. Jakarta: Kencana.

Kuncoro, M. (2006). Strategi-Bagaimana Meraih Keunggulan Kompetitif, Jakarta: Penerbit Erlangga.

Kuncoro, M. 2009. Metode Riset untuk Bisnis dan Ekonomi. Edisi 3. Jakarta: Erlangga.

Kuncoro, M. (2013). Metode Riset Untuk Bisnis \& Ekonomi: Bagaimana Meneliti \& Menulis Tesis, Edisi3, Cetakan 1, Jakarta: Erlangga.

Laksitareni, S. P. (2015). Suksesi Dalam Perusahaan Keluarga: Studi Kasus Tiga Perusahaan Keluarga Di Jawa Tengah. Jurnal Bisnis STRATEGI, 24(2), 47-65.

Mandi, I. (2008), Overview of Family Business Relevant Issues, KMU Forschung Austria, Vienna: Austrian Institute for SME Research.

Marpa, N. (2018). Perusahaan KeluargaSukses Atau Mati. Tangerang: Cergas Media. 
Palupijati， S. \& Indarti, N. (2013). Tata Kelola Pada UKM: Perbandingan Penerapan Pada Bisnis Keluarga dengan Bisnis Non-Keluarga.Thesis. Universitas Gajah Mada.

Pengemanan, S. A. \& Walukow, I. M. (2018). Merketing strategy analysis for small and medium scale business enterprise (SMEs) for home industry furniture in Leilem, The Regency of Minahasa. Journal of Physics: Conf. Series 953-012033.

Pangestika, P., Santoso, I., \& Astuti, R. (2016). Strategi Pengembangan Potensi Usaha Mikro Kecil dan Menengah (UMKM) dengan Dukungan Kucuran Kredit (Studi Kasus: UMKM Kabupaten XYZ), Industria: Jurnal Teknologi dan Manajemen Agroindustri, 5(2), 84-95.

Purwono, J., Sugyaningsih, S., \& Putri, R. T. (2015) Strategi Pengembangan Bisnis Rumah Tempe Indonesia Di Kota Bogor, Propinsi Jawa Barat. Jurnal NeO-Bis: Jurnal Berkala Ilmu Ekonomi, 9(1), 60-71.

Qurashi, A., Hussain, I., Mushtaq, F., \& Ullah, A. (2013). The dilemma of success and failure in family business: Overcoming failure and attaining success. International Journal of Academic Research in Economics and Management Sciences, 2(4). 161-177.

Rahim, A., \& Karana, H. (2014). Karakteristik Operasional Usaha Mikro Di Kota Medan, Seminar Nasional, IENACO. 492-509.

Rahmana, A. Oktarina R., \& Iriani, Y. (2012). Strategi Pengembangan Usaha Kecil Menengah Sektor Industri Pengolahan. Jurnal Teknik Industri, 13(1), 14-21.

Rumanti, A.A \& Syauta, K.J. (2013), Determining strategies based on strategic position analysis in small and medium enterprises, International Journal of Information and Education Technology, 3(4), 442-447.
Singarimbun, M., \& Effendi, S. (2007). Metode Penelitian Survei, Jakarta: LP3ES

Stefan H. S. (2010). A Conceptual View of a Family-Owned Corporation, Makalah dalam Pelatihan yang diselenggarakan oleh Indonesia Institute for Corporate Directorship (IICD), Jakarta.

Steier, L.P., Chrisman, J. J., \& Chua, J. H. (2015), Governance challenges in family business and business families (1265-1289). Baylor University: Entrepreneurship theory and practice,

Sugiyono. (2017). Metode Penelitian Kuantitatif, Kualitatif, dan $R \& D$. Bandung: CV. Alfabeta.

Susanto, A.B. (2005). Wolrd Class Family Business, Jakarta: Penerbit Quantum.

Tugiman, H. (1995). Peranan Usaha Kecil dan Koperasi dalam Memanfaatkan Sisa Laba BUMN, Bandung: Penerbit Eresco

Urata, S., Kyorkoyu, K. \& Jigyodan. (2000). Policy Recommendation: Outline Of Tentative Policy Recommendation For SME Promotion In The Republic Indonesia. Jakarta: JICA (Japan International Cooperation Agency).

Utomo, N. M. (2017). Kajian Strategi Pengembangan Usaha Mikro Kecil dan Menengah (UMKM) Di Kota Tarakan, Jurnal Organisasi dan Manajemen, 13(2), 99-118.

Vani, R., Chandraiah, M., \& Prakāsh, C. (2014). Family business management in small and medium enterprises at Nellore District. International Journal of scientific research and management, 2(8), 1249-1266.

Wahjono, S. I. (2009). Suksesi Dalam Perusahaan Keluarga. Jurnal Balance, 3(1), 1-15. 